\title{
Relief of Acute Chest Syndrome of Sickle Cell Anaemia by Nitric Oxide Inhalation - A Report of 2 Cases
}

Souvik Choudhuri, Banambar Ray and Dipika Mohanty

Hematology, Apollo Hospitals, Bhubaneswar, Odisha, India

"Corresponding author: Dipika Mohanty, Hematology, Apollo Hospitals, Bhubaneswar, Odisha, India, Tel: +918093060025; E-mail: mohantydipika09@gmail.com

Received Date: Apr 06, 2018; Accepted Date: Apr 25, 2018; Published Date: May 04, 2018

Copyright: (c) 2018 Choudhuri S, et al. This is an open-access article distributed under the terms of the Creative Commons Attribution License, which permits unrestricted use, distribution, and reproduction in any medium, provided the original author and source are credited.

\begin{abstract}
Depletion of nitric oxide (NO) in the microcirculation plays a central role in the pathogenesis of sickle cell disease (SCD) and acute chest syndrome (ACS). Various other mechanisms which are responsible for the sickle-cell vasoocclusive crisis are polymerization of sickle haemoglobin, platelet activation, endothelial damage and leucocyte adhesion. During the sickle cell crisis, the high rate of red blood cell (RBC) destruction leads to release of erythrocyte arginase (into the plasma), which thereby destroys arginine. Arginine, the substrate for NO synthase, once depleted, results in lower levels of $\mathrm{NO}$ in vessels, leading to vasoconstriction, pulmonary hypertension and ventilation perfusion mismatch. Increasing the availability of NO therefore has a central role in SCD, especially in cases of ACS. With the prevention of vasoconstriction by NO inhalation therapy in ACS, pain relief can be provided to the patients in sickle cell crisis. We present a report of 2 cases of sickle cell disease with ACS (Acute Chest Syndrome) in whom inhalation of NO through non-invasive ventilation (NIV) brought about pain relief and recovery from ACS.
\end{abstract}

\section{Introduction}

In patients with sickle cell disease (SCD), hypoxic conditions lead to polymerization of haemoglobin $S$ in red blood cells (RBCs), ultimately resulting in the occlusion of blood vessels [1]. Polymerization of haemoglobin S in the RBCs leads to a change in morphology to make it a crescent or sickle shape, which is more rigid than the normal RBC. This change results in hemolysis, inflammation, adhesion of RBC and end organ ischemic reperfusion injury leading to infarct [2]. The release of haemoglobin, as a result of hemolysis, rapidly consumes nitric oxide, resulting in a whole sequence of events that inhibit blood flow. The increased rate of destruction of the deformed RBCs in patients with SCD, releases erythrocyte arginase into plasma, which decreases the arginine levels in blood. Arginine, being the substrate for NO synthase, once depleted, leads to reduction in NO levels. The pathophysiology of acute chest syndrome (ACS) revolves around the depletion of $\mathrm{NO}$ in pulmonary vessels, leading to pulmonary vasoconstriction and chest pain [3]. Therapies which decrease the destruction of nitric oxide (NO) as well as increase the production of $\mathrm{NO}$, will be useful in patients of SCD who are in ACS. NO which has the ability to decrease the polymerization of RBCs, reduces pulmonary hypertension and ventilation - perfusion mismatch and therefore is beneficial in patients with ACS3.

A review of literature shows conflicting results with regards to utility of NO in SCD pain crisis and ACS. There are studies, which suggest that NO holds considerable promise in vaso-occlusive crisis of SCD $[3,4]$. A recent large multicentred controlled trial with NO however, has shown no benefit in adults with SCD with acute pain crises [5].

We present a report of 2 cases where inhaled NO through noninvasive ventilation (NIV) successfully provided relief to patients in ACS.

\section{Case Report}

\section{Case 1}

A 31 year male patient of SCD by the name P.B. of SCD, was admitted to the hospital on 25th Aug, 2013 with complaints of bilateral chest pain, low grade fever, body aches and jaundice for 3-4 days. On arrival at Emergency room, he was in respiratory distress, with a respiratory rate of $40 / \mathrm{min}$ and on room air, oxyhaemoglobin saturation $\left(\mathrm{HbSaO}_{2}\right)$ was $88-89 \%$. Arterial blood gas analysis showed $\mathrm{pH} 7.33, \mathrm{PaCO}_{2} 41 \mathrm{mmHg}, \mathrm{PaO}_{2} 77 \mathrm{mmHg}$ (with $30 \%$ inspired oxygen concentration), $\mathrm{HCO}_{3} 22 \mathrm{mEq} / \mathrm{L}$ and a lactate of $2.3 \mathrm{mmol} / \mathrm{L}$. Other investigations revealed a total bilirubin of $28.2 \mathrm{mg} / \mathrm{dL}$ (direct $15.8 \mathrm{mg} /$ $\mathrm{dL})$, raised alkaline phosphatase $(725 \mathrm{U} / \mathrm{l})$, and raised liver enzymes (ALT $640 \mathrm{U} / \mathrm{L}$ and AST $902 \mathrm{U} / \mathrm{L}$ ). The total leucocyte count (TLC) was $17,200 / \mathrm{mm}^{3}$ with haemoglobin of $8.9 \mathrm{gm} / \mathrm{dL}$. Chest X-ray revealed right lower zone homogenous opacities. He was admitted with the diagnosis of ACS and immediately given NIV with pressure support of $14 \mathrm{~cm} \mathrm{H}_{2} \mathrm{O}$ and a positive end expiratory pressure of $5 \mathrm{~cm} \mathrm{H}_{2} \mathrm{O} . \mathrm{He}$ was put on antibiotics 'piperacillin tazobactam' along with levofloxacin. After noting Verbal Analogue Score [6] (VAS) he was started on inhalational NO therapy through NIV. Each session started with NO being delivered through a face mask from a Hamilton ventilator and the NO apparatus Inosys, with the target $\mathrm{NO}$ level of 80 parts per million parts (ppm). A written informed consent was taken prior to administration of inhaled NO. Since NO concentration was falling below the desired level due to hyperventilation (minute ventilation $>10 \mathrm{~L} / \mathrm{min}$ ), the patient was given midazolam intravenous boluses of $0.05 \mathrm{mg} / \mathrm{kg}$ to decrease the minute ventilation, thereby again attaining the desired NO target levels. Pain scores were monitored using verbal analogue score (VAS) of $0-10$, where the patient was explained that a score of 0 meant no pain at all, and a score of 10 meant unbearable agonising pain. The patient's heart rate, blood pressure, minute ventilation, oxygen saturation were monitored 
continuously but recorded at 15 minutes interval. At the end of a 4 hour session of inhalation NO, the patient's pain score was compared to the initial pain score.

After 6 hours of inhalation of NO therapy at $80 \mathrm{ppm}$, the pain score due to ACS decreased from initial $6 / 10$ to $1 / 10$. He received another session of inhaled NO therapy on the third day after his admission, when the pain score decreased from $5 / 10$ to $1 / 10$ at the end of a 4 hour session. His repeat chest X-ray showed clearance of pulmonary infiltration in both lungs. He was discharged after 11 days of hospital stay as his condition improved.

\section{Case 2}

A 22 years male patient with a case of SCD (diagnosed 3 years back) presented to the Emergency department of Apollo Hospital, BBSR on 12th June, 2013 with complains of Low back pain and pain in multiple joints for 3 days, breathing difficulty and altered sensorium for 2 days. He was initially admitted in the MKCG Medical College Hospital, Berhampur (nearly $200 \mathrm{KM}$ away from Bhubaneswar) and was intubated there in view of persisting respiratory distress. He was referred to us for further management. He had no history of fever/ vomiting/convulsion/loss of consciousness. On arrival, he was restless, disoriented, moving all 4 limbs. GCS: E(2), V(T), M(5), BP: 140/80 mslg, PR: 154/min., RR: 26/min, Temp: 1010F, Icterus+, Pallor+ and ABG: showed severe lactic acidosis. Investigations revealed moderate anemia (Hb: 6.9 gm\%), Resp. Failure with Hypoxemia (Rt. Lower zone pneumonia in chest X-ray (A-P view), renal dysfunction: (S.Cr: 1.9 $\mathrm{mg} / \mathrm{dl}, \mathrm{SK}+: 7.0 \mathrm{mmol} / \mathrm{L}, \mathrm{S} . \mathrm{Na}: 123 \mathrm{mmol} / \mathrm{L}$ ), hepatic dysfunction (S. Bilirubin: $8.3 \mathrm{mg} / \mathrm{dl}$ (dir: $1.7 \mathrm{mg} / \mathrm{dl}$, indirect: $6.6 \mathrm{mg} / \mathrm{dl}$ ), GGTP: 18 U/L, ALP: $476 \mathrm{U} / \mathrm{L}$ ) TLC 47,800/cumm of blood, CRP: $123 \mathrm{mg} / \mathrm{L}$, Procalcitonin $>10 \mathrm{ng} / \mathrm{ml}$, CT chest: bilateral lower lobe and one segment of right upper lobe having inhomogeneous consolidation and USG Abd: gross splenomegaly with mild hepatomegaly, globular and hypoechoic kidneys with prominent CMD suggestive of acute renal failure (ARF).

He was managed initially in ICU with mechanical ventilation and nitric oxide inhalation for 6 hours twice, extubated on 20/06/2013 after 8 days and kept on intermittent NIV support till 22nd June, 2013 along with I.V. antibiotics i.e. Inj. Meropenem, Inj. Cefoperazome +sulbactam, Inj. Targocid and Inj. Levofloxacin. He was transfused with 3 units of PRC for improving his anemia. Gradually his clinical and laboratory parameters improved, his pain subsided and he was discharged on 5th July, 2013.

\section{Discussion and Conclusion}

Acute chest syndrome is the most common cause of death in patients with SCD. Pain is an initial prodromal symptom of ACS and up to $50 \%$ of patients of ACS have painful crisis at presentation [7]. Dyspnea and pain in chest are the commonest symptoms of ACS in adults [8]. Therapy for ACS is mainly supportive which comprises of bronchodilators, antibiotics to prevent bacterial infections, mechanical ventilation and exchange transfusions [9].

One study has shown that sickle cell anaemia is associated with decreased NO bioactivity in both peripheral conduit as well as in resistance vessels [10]. In this study, the authors had measured the effects of intra-arterial infusion of methacholine and sodium nitroprusside (SNP) on forearm blood flow using venous occlusion plethysmography in $8 \mathrm{HbSS}$ patients and $11 \mathrm{HbAA}$ controls and found that the blood flow response to sodium nitropruside was greater in HbSS patients than in controls.

It has been postulated that NO has multiple beneficial effects which enhance blood flow and suppress platelet aggregation and procoagulant substances [11-13]. In a 30 centre study involving 671 episodes of ACS in 538 patients, it was shown that nearly $50 \%$ of patients admitted with ACS had pain as the presenting symptom [14]. Patients more than 20 years of age, presence of extensive lobar pulmonary involvement and history of any cardiac disease were independent risk factors for respiration failure during hospital stay. The cause of ACS was unknown in $45.7 \%$ patients in that study with pulmonary infarct being the second leading cause (16.1\%). Bacterial infections were the cause of ACS in $4.5 \%$ in patients. As pulmonary infarct was the second leading cause of ACS (apart from unknown cause contributing to the largest number of ACS cases), the significance of NO to relieve the vasospasm in pulmonary vessels (and hence pulmonary infarct) was of paramount importance as concluded in the study.

One trial has shown that there is a significant reduction with NO administration in the severity and duration of pain due to the vasoocclusive crisis in sickle cell disease affecting children [15]. Inhaled NO reduces pulmonary artery pressures and improves ventilationperfusion matching and oxygenation.

Some of the earlier studies have shown that NO has a beneficial effect in patients with SCD in the early resolution of vaso-occlusive crisis and acute chest syndrome $[4,13]$. In the study done by Reiter et al. [13] the authors had concluded that inhaled NO improves pulmonary ventilation-perfusion matching, reduces alveolar and systemic inflammation, inhibits circulating plasma haemoglobin, and therefore ultimately modulates the course of the disease. Likewise one case report mentions about successful treatment of ACS by inhaled NO in a concentration of $20 \mathrm{ppm}$ for 72 hours [16]. Another case report finds that there is improvement in ACS by inhalation of NO @ 80 ppm for 72 hours [17]. Likewise, yet another study revealed that inhaled NO led to lowered requirement of analgesic therapy in children [14]. Another study on twenty patients aged 10-21 years found significant reduction in pain scores in the inhaled NO group at 4 hours and less opioid requirement [4].

On the contrary, one study revealed no benefit in adults in acute pain crisis [5]. In this study with 150 patients of SCD with vasoocclusive crisis (VOC), a lower concentration of NO with lesser ppm could have been one of the reasons for ineffective NO therapy.

The results in both the cases in which we administered inhaled NO were very good and both the patients had pain relief and complete resolution of the painful ACS. We had also reported in our earlier study the beneficial effects of $\mathrm{NO}$ inhalation in relieving acute pain in VOC of SCD [18]. We followed up both the patients after they were discharged from the hospital after successful NO therapy.

The advantages of inhalation NO therapy are (i) it can be easily administered in a patient via the non-invasive ventilator (ii) it leads to an early relief in painful crisis, (iii) it decreases opioid requirement and (iv) it can be given on a day-care basis i.e. after a 4-6 hours therapy, the patient can be discharged home. However, during the administration of inhalation of $\mathrm{NO}$, the patient requires intensive monitoring of vitals including oxygen saturation, ventilation related parameters and NO concentration, which is dependent on patient's minute ventilation. 
Citation: Choudhuri S, Ray B and Mohanty D (2018) Relief of Acute Chest Syndrome of Sickle Cell Anaemia by Nitric Oxide Inhalation - A Report of 2 Cases. Med Rep Case Stud 3: 156. doi:10.4172/2572-5130.1000156

Page 3 of 3

We recommend that there should be a multicentric clinical trial with inhaled NO in Indian patients to establish the efficacy of inhaled NO under varying conditions, its optimum concentration in inhaled mixture and its duration of exposure.

\section{References}

1. Scheter AN, Noguchi CT (1994) Sickle Hg Polymer. In: Embury SH Hebbel RP, Mohandas N, Steingberg MH (eds.) Sickle cell disease: basic principles and clinical practice. Raven Press, New York, USA.

2. Platt OS (2000) Sickle cell anemia as an inflammatory disease. J Clin Invest 106: 337-338.

3. Hebbel RP (2014) Ischemia-reperfusion injury in sickle cell anemia. Relationship to Acute Chest Syndrome, endothelial dysfunction, arterial vasculopathy and inflamamatory pain. Hematol Oncol Clin N Am 28: 181-198.

4. Head CA, Swerdlow P, McDade WA, Joshi RM, Ikuta T, et al. (2010) Beneficial effect of nitric oxide breathing in adult patients with sickle cell crisis. Am J Hematol 85: 800-802.

5. Gladwin MT, Kato GJ, Weiner D, Onyekware OC, Dampier C, et al (2011) Nitric Oxide for inhalation in the acute treatment of sickle cell pain crisis: A randomized clinical trial. JAMA 305: 893-902.

6. Ballas SK, Delengowski A (1993) Pain measurement in hospitalized adults with sickle cell painful episodes. Ann Clin Lab Sci 23: 358-361.

7. Castro O, Brambilla DJ, Thorington B, Reindorf CA, Scott RB, et al. (1994) The acute chest syndrome in sickle cell disease: Incidence and risk factors. The cooperative study of Sickle Cell Disease. Blood 84: 543-549.

8. Vichinsky EP, Styles LA, Colangelo LH, Wright EC, Castro O, et al. (1997) Acute chest syndrome in sickle cell disease: clinical presentation and course. Cooperative study of Sickle Cell Disease. Blood 89: 1787-1792

9. Steinberg MH (1999) Management of sickle cell disease. N Engl J Med 340: 1029-1045.
10. Eberhardt RT, McMahon L, Duffy SJ, Steinberg MH, Perrine SP, et al. (2003) Sickle cell anemia is associated with reduced nitric oxide biperipheral conduit and resistance vessels. American Journal of Hematology 74: 104-111.

11. Kahn MJ, Maley JH, Lasker GF, Kadowitz PJ (2013) Updated Role of Nitric Oxide in Disorders of Erythrocyte Function. Cardiovasc Hematol Disord Drug Targets 13: 83-87.

12. Hebbel RP, Schwartz RS, Mohandas N (1985) The adhesive sickle erythrocyte cause and consequence of abnormal interactions with endothelium, monocytes; macrophages and model membrances. Clin Hematol 14: 141-161.

13. Reiter CD, Wang X, Tanus-Santos JE, Hogg N, Cannon RO, et al. (2002) Cell-free haemoglobin limits nitric oxide bioavailability in sickle cell disease. Nat Med 8: 1383-1389.

14. Vichinsky EP, Neumayr LD, Earles AN, Williams R, Lennette ET, et al. (2000) National Acute chest syndrome study Group, Causes and outcomes of the acute chest syndrome in sickle cell disease. N Engl J Med 342: 1855-1865.

15. Weiner DL, Hibberd PL, Betit P, Cooper AB, Botelho CA, et al. (2003) Preliminary assessment of inhaled nitric oxide for acute vaso-occlusive crisis in pediatric patients with sickle cell disease. JAMA 289: 1136-1142.

16. Sullivan KJ, Goodwin SR, Evangelist J, Moore RD, Mehta P, et al. (1999) Nitric oxide successfully used to treat acute chest syndrome of sickle cell disease in a young adolescent. Crit Care Med 24: 2563-2568.

17. Atz AM, Wessel DL (1997) Inhalad nitric oxide in sickle cell disease with acute chest syndrome. Anesthesiology 87: 988-990.

18. Mohanty D, Ray B, Pattanayak SS (2015) Effect of Nitric Oxide inhalation in acute pain crisis of Sickle Cell Disease: a preliminary report: Journal of Hematology \& Thromboembolic Diseases 3: 1-5. 